\title{
"A força da juventude garante o futuro de um povo": a educação do corpo no Sport Club Germania (1899-1938) ${ }^{1}$
}

\author{
Evelise Amgarten Quitzau * \\ Carmen Lúcia Soares**
}

\begin{abstract}
Resumo: Este estudo teve como objetivo compreender as práticas corporais desenvolvidas no Sport Club Germania e observar suas possíveis relações com a ginástica desenvolvida largamente na Alemanha ao longo do século XIX, século que marca um período de intensa imigração europeia em direção ao Brasil. Dentre as ondas migratórias que aqui chegaram, podemos destacar as alemãs que, embora mais intensas na região sul, também tiveram grande importância na formação de São Paulo. Entre as variadas instituições fundadas por tais imigrantes na capital paulista, os clubes tiveram grande destaque como referências tanto para a prática de exercícios físicos quanto para a manutenção das tradições germânicas.

Palavras-chave: Práticas corporais. Imigração alemã. Esporte.
\end{abstract}

\section{INTRODUÇÃO}

Ao longo do século XIX, o Brasil recebeu um grande contingente de imigrantes oriundos de diversos países da Europa, entre eles, da Alemanha ${ }^{2}$. Esta população vinha em busca de novas possibilidades

\footnotetext{
*Mestranda em Educação Física. UNICAMP. Campinas, SP, Brasil. E-mail: eveliseaq@yahoo.com.br

**Professora do Programa de Pós-Graduação da Faculdade de Educação e da Faculdade de Educação Física da UNICAMP. Campinas, SP, Brasil. E-mail: carmenls@unicamp.br ${ }^{1}$ Este trabalho é resultado de pesquisa de Iniciação Científica financiada pelo CNPq, posteriormente transformada em monografia intitulada "As práticas corporais no Sport Club Germania (1900-1943)", (Monografia). Campinas: Faculdade de Educação Física/Unicamp, 2008

"A força da juventude garante o futuro de um povo" está presente no artigo "Sport-Club Germania, São Paulo - Werden, Arbeit, Zweck und Ziel", escrito por Hermann Thümmel, publicado na Revista Sport Club Germania de 1929, p.14.

${ }^{2} E$ importante lembrar que, no início do século XIX, a Alemanha ainda não era um Estado único, mas um conglomerado de principados autônomos. Além disso, durante as primeiras décadas do século XIX, parte do território estava sob domínio napoleônico, e as constantes derrotas sofridas pelas tropas prussianas nas tentativas de expulsar os franceses fizeram com que surgisse, na Alemanha, um movimento em busca de sua libertação, que acontecerá apenas em 1813.
} 
de trabalho, atraída pela propaganda do governo nacional e dos agentes de imigração, bem como pela promessa de melhores condições de vida, uma vez que, em sua terra natal, as perspectivas eram cada vez mais desanimadoras. O processo de industrialização na Alemanha trouxe diversos impactos à estrutura econômica; as corporações de ofício foram suprimidas pelo trabalho mecanizado, e aqueles que conseguiram se inserir nessa nova e crescente indústria tiveram de se sujeitar a condições de trabalho deploráveis (SIRIANI, 2003).

Os primeiros imigrantes alemães chegaram a São Paulo em 1827. O núcleo de Santo Amaro, para onde foram enviados, inicialmente recebeu apoio e incentivo governamental, mas logo foi deixado à sorte. Alguns imigrantes continuaram na região, mas muitos migraram para a cidade, onde voltaram a exercer os ofícios que haviam aprendido na terra natal.

As condições em que os imigrantes foram deixados no núcleo de Santo Amaro, a exploração à qual foram submetidos nas fazendas de café e as dificuldades encontradas para iniciar sua vida no novo país chegaram ao conhecimento do governo prussiano que, em 1859, decretou a Restrição de Heydt, que impedia a emigração dos alemães para o Brasil. O decreto foi mantido até 1871 e, embora não tenha significado o fim da emigração para o Brasil, levou a uma drástica redução no número de imigrantes que entraram em nosso país. Após o fim da Restrição de Heydt, houve novo crescimento no número de imigrantes alemães que chegaram ao Brasil, porém esse índice permaneceu abaixo daquele existente antes da restrição.

Independentemente do período em que chegaram os imigrantes, a busca pela manutenção de sua cultura sempre foi muito forte, sendo a língua comum um dos fatores mais significativos na constituição desses laços. Para os alemães o mais importante não era a região exata de onde cada família tinha vindo, mas o fato de falarem a mesma língua, terem os mesmos costumes e, principalmente, terem o mesmo sangue. Segundo Seyferth (apud SIRIANI, 2003, p.43)

[...] a palavra "origem" é o elemento fundamental de qualquer distinção étnica e está ligada à idéia de 
herança de sangue e não ao território de procedência dos ascendentes. Nesse caso, uma pessoa é, em princípio, definida pela origem étnica, pelo fato de pertencer a um povo. $O$ fato de alguém ter nascido no Brasil, em Baden ou na Prússia não tem significação alguma, desde que seu "sangue" seja alemão.

Buscando manter essas tradições e esses costumes, os imigrantes alemães fundaram diversas associações educacionais, religiosas, de auxílio e recreativas, onde tinham como objetivo propiciar aos seus descendentes de sangue alemão a oportunidade de crescerem, serem educados e criados conforme as tradições germânicas, dentre as quais podemos destacar a prática da ginástica.

A ginástica desenvolveu-se na Alemanha ao longo do século XIX a partir do trabalho de Guts Muths e Jahn, cujos objetivos eram, principalmente, o fortalecimento físico e moral da população. Embora os exercícios propostos por ambos fossem, em muitos casos, os mesmos, os trabalhos diferenciavam-se em um ponto importante: o discurso patriótico inserido no trabalho de Jahn.

A obra de Johann Friedrich Cristoph Guts Muths (1759-1839) teve grande importância no desenvolvimento da ginástica. Esse teólogo e pedagogo foi professor de ginástica do Philantropinum de Schnepfenthal. Baseado em sua experiência nessa instituição escolar que ele escreveu, em 1793, Gymnastik für die Jugend ${ }^{3}$ (Ginástica para a Juventude, tradução livre), considerado o primeiro tratado sobre o assunto (LEONARD, 1927, p.77).

Em Ginástica para a Juventude, Guts Muths afirma estar:

[...] ciente de que uma verdadeira teoria da ginástica deveria ser elaborada baseada em princípios fisiológicos, e a prática de cada exercício regulada pelas qualidades físicas de cada indivíduo, mas tal perfeição não é esperada deste trabalho, feito somente pela genuína experiência de 8 anos de prática, que

3Utilizo a tradução inglesa do livro, Gymnastics for Youth, de 1800.

Wovimento, Porto Alegre, v. 16, n. 03, p. 89-108, julho/setembro de 2010. 
me convenceram que a ginástica é necessária è educação $[\ldots]^{4}$ (GUTS MUTHS, 1800, p. VIII), (tradução livre).

Essa "imperfeição" apontada por Guts Muths em seu trabalho é logo por ele justificada ao afirmar que "requerer um tratado de ginástica, portanto, baseado na anatomia e fisiologia, seria inconsistente com as presentes circunstâncias" (GUTS MUTHS, 1800, p.IX). Assim, uma teoria ginástica estritamente baseada em preceitos biológicos não era suficiente: era necessário adaptá-la às circunstâncias.

Buscando a inserção da ginástica como parte fundamental da educação dos jovens e um retorno à natureza, Guts Muths buscou basear suas ideias nos trabalhos de Rousseau e de teóricos da polícia médica ${ }^{5}$. Influenciado por Rousseau, defende o homem como uma unidade física e mental, citando passagens de O Emílio como "quanto mais fraco o corpo mais ele comanda; quanto mais forte, mais obedece" (GUTS MUTHS, 1800, p.73), ou, "um corpo fraco enfraquece a alma" (GUTS MUTHS, 1800, p.83). Sua busca por um retorno à natureza também o leva a constantes comparações entre homens e natureza, como se pode observar na seguinte passagem, em que trata das relações corpo e mente:

Destrua as raízes das plantas mais saudáveis que elas inclinarão e morrerão. Muitas excelentes qualidades da mente têm suas raízes, na verdade, no corpo. Os vértices que adornam o ser espiritual, a mente, definharão se negligenciarmos o solo destas plantas valiosas e, assim, machucarmos suas raízes. (GUTS MUTHS, 1800, p.81) .

\footnotetext{
4"I am aware, that a genuine theory of gymnastics should be constructed on physiological principles, and the practice of each exercise be regulated by the physical qualities of each individual: but such perfection is not to be expected in the following work built solely on the genuine experience of eight years practice, which has convinced me, that gymnastics are necessary to education..."

${ }^{5} \mathrm{~A}$ polícia médica era definida como "uma ciência que ensina a aplicar os princípios médicos e dietéticos à promoção, manutenção e recuperação da saúde pública." (HEBENSTREIT apud ROSEN, 1980, p.175). A partir das informações fornecidas pelos médicos sobre a dinâmica da saúde da população eram emitidas as ordens necessárias para a realização dos trabalhos.

${ }^{6}$ "Destroy the roots of the healthiest plants, their heads will droop and die. Many excellent qualities of the mind have their roots, in fact, in the body: their summits, which adorn the spiritual being, the mind, will wither if we neglect the soil of these valuable plants, and thus injure there roots."
} 
Outra referência constante no trabalho de Guts Muths era Johann Peter Frank, autor de uma das principais obras da polícia médica: Sistema de Polícia Médica ${ }^{7}$. É principalmente nessa obra que o pedagogo alemão encontra as bases médicas para justificar a inserção da ginástica na educação da juventude. Segundo citação de Frank feita por Guts Muths,

Em todas as cidades, os mestres das escolas deveriam acompanhar seus alunos, sem exceção, ao campo aberto, regular seus jogos e supervisionar seus exercícios; ou, o que eu prefiro aconselhar, um mestre seria designado especialmente para ginástica, e teria como única tarefa aplicar os exercícios destinados à juventude. (FRANK, v.2, p.629 apud GUTS MUTHS, 1800, p.120).

Observa-se, portanto, que na obra de Guts Muths, as questões relativas à melhoria da saúde, das capacidades e das destrezas físicas são peças-chave para a defesa da implantação da ginástica e foram fundamentais para sua aceitação entre a burguesia alemã (TESCHE, 2002).

Ao longo do século XIX, contudo, observa-se um declínio das proposições elaboradas por Guts Muths acerca da ginástica, proposições que serão em curto espaço de tempo suprimidas e substituídas por outra sistematização das atividades físicas: o Turnen.

Desenvolvido por Friedrich Ludwig Jahn (1778-1852), o Turnen era carregado de um discurso fortemente patriótico e nacionalista, o que contribuiu para sua maior aceitação e disseminação entre a população alemã. Enquanto Guts Muths pensava em termos escolares, Jahn visava uma educação física para toda a população, sem distinções de classe (DIXON, 1981). O que Jahn pretendia era, a partir da ginástica, formar indivíduos com capacidade para o exército, com "força e vigor [...], resistência e persistência, [...] agilidade e prestabilidade" (TESCHE, 2002, p.83). Com o preparo físico, buscava-se o preparo interior, a moral, características essenciais para quem terá como tarefa defender a pátria.

${ }^{7}$ System einer vollständigen medicinischen Polizey, escrito pelo médico Johann Peter Frank e publicado na Alemanha em 1779.

Wovimento, Porto Alegre, v. 16, n. 03, p. 89-108, julho/setembro de 2010. 
O próprio nome da metodologia desenvolvida por Jahn já indica o quanto este pedagogo da ginástica buscava exaltar sua nação. Segundo Pfister (2000), a palavra Turnen foi criada por Jahn para substituir o termo Gymnastik, de origem grega, em sua busca de livrar a língua alemã de estrangeirismos. Podemos observar claramente esse desejo de Jahn em preservar a língua alemã de todo estrangeirismo logo nas primeiras páginas de seu livro Die Deutsche Turnkunst (A Ginástica Alemã, tradução livre), no qual defende ser:

[...] um direito incontroverso denominar um assunto alemão em língua alemã, uma obra alemã com palavras alemãs. Por que ir mendigar por palavras estrangeiras, e tomar emprestado do estrangeiro, $\mathrm{o}$ que se tem abastadamente e melhor na Pátria?

\section{$[\ldots]$}

A língua alemã associa pura originalidade com continuidade de formação, e antiguidade com alegria juvenil. [...] Sua grande riqueza em palavras originais the dá firme preponderância. (JAHN, 1816, p.XIX e p.XXII) ${ }^{8}$

Assim, do radical turn, derivam-se mais de 60 palavras para designar pessoas, locais e objetos que tivessem alguma ligação com o método. O ginasta passou a ser chamado de Turner e o local de ginástica foi denominado Turnplatz. No Turnen de Jahn, o pensamento nacionalista impresso à juventude pelos filósofos da época encontra um efetivo meio de ação. Segundo Elias (1997), o Turnen de Jahn era um movimento muito mais político do que propriamente ginástico.

A rápida disseminação da ginástica, em especial do Turnen, contribuiu para sua grande aceitação entre a população. Consequentemente, quando as ondas migratórias se iniciaram, esta prática acompanhou seus imigrantes e enraizou-se nos diferentes paises que os acolheram. Segundo Nicolini (2001), há registros da

\footnotetext{
8"Es ist ein unbestrittenes Recht, eine Deutsche Sache in Deutscher Sprache, ein Deutsches Werk mit Deutschem Wort zu bennenen. Warum auch bei fremden Sprachen betteln gehen, und im Ausland auf Leih und Borg nehmen, was man im Vaterlande reichlich und besser hat.

[...]

Die Deutsche Sprache vereint reine Ursprünglichkeit mit Weiterbildsamkeit, und hohes Alter mit jugendlicher Frische."
} 
prática da ginástica no interior de São Paulo já em 1841, pouco tempo após a chegada do primeiro grupo de imigrantes à fazenda Ibicaba (região de Limeira). Na cidade de São Paulo observa-se, ao longo do século XIX, a fundação de inúmeras associações alemãs voltadas a distintas práticas corporais, como por exemplo o Deutscher Turnverein (1888), o Turnerschaft von $1890^{9}$ e o Sport Club Germania (1899), sendo que nos dois primeiros a prática do Turnen era bastante presente.

Este trabalho busca compreender as práticas corporais no Sport Club Germania, importante ponto de referência da colônia alemã de São Paulo e cujas origens não se baseiam na prática da ginástica.

\section{Clube}

Ao contrário do que aconteceu com o Deutscher Turnverein e o Deutsche Turnerschaft que, como os próprios nomes indicam, tinham como objetivo a prática do Turnen em solo brasileiro, o Sport Club Germania surgiu a partir do interesse por outra prática corporal: o futebol.

Quando o imigrante alemão Hans Nobiling (1877-1954) chegou ao Brasil, em 1897, sua preocupação inicial foi a de procurar outros companheiros com os quais pudesse dar continuidade à prática do futebol, esporte que praticava no S.C. Germania de Hamburgo, sua cidade natal. Para sua decepção, entretanto, não havia na colônia alemã de São Paulo outras pessoas que tivessem jogado o futebol anteriormente. "Fazer gymnastica, sim, mas jogar futebol ninguém queria aprender", afirma em seu relatório sobre a origem do futebol na cidade.

Inicialmente, assistiu a alguns jogos na colônia inglesa, mas afirma que mesmo entre os britânicos o futebol não era tão praticado, uma vez que o cricket tinha a preferência entre eles. Somente em meados de 1898 Nobiling encontra conterrâneos que sabiam e tinham interesse em continuar a praticar o futebol. Treinavam nos

9Sociedade Ginástica Alemã e Associação Ginástica 1890.

Wovimento, Porto Alegre, v. 16, n. 03, p. 89-108, julho/setembro de 2010. 
feriados e aos finais de semana, e logo começaram a procurar adversários com os quais pudessem jogar.

Em agosto de 1899 convocou-se a primeira reunião entre os moços que jogavam o futebol na colônia de São Paulo com o intuito de fundar um clube. Deliberada sua fundação, procedeu-se a escolha do nome. Duas propostas foram colocadas em votação: S.C. Internacional e S.C. Germania, sendo a segunda elaborada por Nobiling. A votação final deu a vitória para a primeira proposta, portanto, Nobiling sai derrotado e, mais que tudo, decepcionado com essa "derrota", vista por ele como uma espécie de esquecimento por parte de toda a comunidade, de seu trabalho realizado nos anos anteriores, um trabalho em vão em sua visão. Assim, decidiu, então, afastar-se com os irmãos Hermann e Rudolf Wahnschaffe que o acompanharam na fundação do S.C. Internacional. Imbuído de seus antigos ideais, alguns dias depois, mais precisamente em 7 de setembro de 1899, funda o do Sport Club Germania.

O clube irmão do Germania de Hamburgo, tão idealizado por Nobiling, finalmente começava a tomar forma. A leitura de seus estatutos permite conhecer o objetivo do clube, qual seja, promover os esportes por meio de jogos e corridas, assembleias periódicas, reuniões sociais e excursões. Desde o início de sua fundação, o Germania foi filiado à Liga Paulista de Foot-ball e em seu primeiro estatuto encontramos ${ }^{10}$ as especificações de seus primeiros departamentos: o de remo e o de tênis ${ }^{11}$, portanto, de um clube voltado, fortemente, às práticas esportivas.

Após um grande período de crescimento e prosperidade, em parte devido ao trabalho de Max Engelhardt ${ }^{12}$ (1874-1959), o Germania depara-se, no final da década de 1930, com um problema que poderia ocasionar o seu fechamento: o Decreto-Lei 383, de 18 de abril de 1938, decreto que obrigava as entidades fundadas por imigrantes a se declararem nacionais ou estrangeiras. Embora sócios não-alemães fossem aceitos e não houvesse nenhuma

\footnotetext{
${ }^{10}$ Datado de 1903 e registrado em cartório em 1904.

${ }^{11} \mathrm{O}$ departamento de tênis era o único que admitia a participação de mulheres.

${ }^{12}$ Presidente do clube na década de 1920.
} 
indicação em seus estatutos de que o clube fosse uma associação alemã, seria necessário esclarecer esta questão para que o Germania pudesse permanecer em funcionamento. Em assembleia, os sócios deveriam escolher entre duas propostas: a declaração do Germania como uma corporação estrangeira ou sua nacionalização. Caso optassem pela primeira, o clube enfrentaria uma grande queda em seu quadro de associados, uma vez que muitos deles eram nascidos no Brasil, ou, naturalizados brasileiros e, principalmente, seus filhos, brasileiros, não poderiam mais usufruir a estrutura do clube. Caso optassem pela nacionalização, eles precisariam apenas fazer algumas alterações em seus estatutos e, dessa forma, poderiam manter varias de suas tradições, assim como a possibilidade de que seus filhos pudessem, também, usufruir da estrutura do clube sendo seus sócios. Uma assembleia realizada em setembro de 1938 com a presença de 223 associados, votou, então, o destino do clube. Porém, antes da votação, ainda foi lida uma carta de Engelhardt, ex-presidente, na qual expressava sua contrariedade à ideia de nacionalização do Germania, defendendo sua caracterização como entidade estrangeira. Ao final da reunião, com um total de 126 votos contra 95, optou-se pela nacionalização do clube, cujo processo teve, de imediato, a mudança de seu nome que passa, então, a ser Esporte Clube Pinheiros.

\section{3 "O Germania chama!"13}

A década de 1920 marca o período de maior crescimento do clube, momento em que o Germania, após cancelar o contrato de arrendamento do Parque Antarctica, comprou uma área abundantemente arborizada, inicialmente com 100.000 metros quadrados, às margens do rio Pinheiros. Já em 1923 foi inaugurado o cocho de natação e, ao longo dessa década, o clube foi-se transformando em uma megaestrutura. Parte dessa transformação, sem dúvida, pode ser atribuída aos trabalhos de Max Engelhardt, claramente envolvido com o desenvolvimento de práticas corporais desde sua atuação

\footnotetext{
${ }^{13}$ Germania ruft!, título de artigo da revista 25 Jahre Sport Club Germania, de 1924.
} 
como presidente do Turnerschaft von 1890, sendo seu nome, portanto, muito conhecido entre os membros da colônia alemã de São Paulo. No Germania, além da contribuição direta no crescimento da infraestrutura do clube, Engelhardt também participava ativamente de suas publicações. Era comum encontrar textos escritos por ele tanto em publicações próprias do clube quanto em outras mais abrangentes, que circulavam por toda a colônia alemã.

No que se refere às publicações do Germania, é possível inferir que elas não tinham como ponto central promover o clube e sua estrutura; seu objetivo era discorrer sobre os benefícios dos exercícios físicos, esportivos ou não, e divulga-los na Colônia bem como fora dela. Se no Turnerschaft e no Turnverein o fortalecimento físico, a formação moral e a manutenção das tradições e do patriotismo germânico eram objetivos a serem alcançados a partir das práticas corporais, particularmente a ginástica, no Germania tais objetivos não apareciam claramente em seus estatutos, mas, sim, em suas publicações. Podemos tomar como exemplo a Revista Sport Club Germania de 1929 que afirma ser um sólido objetivo do clube "a educação física de nossa juventude em terra estrangeira" (p.50). Esse periódico também discorre mais amplamente em relação ao ideário patriótico germânico quando refere-se a necessidade de se:

[...] produzir efeito atrativo e unificador para a centralização de todas as forças da colônia alemã, que deve intervir coerentemente no sublime ideal de conservar o pensamento na Pátria e também manter a preciosa característica da raça alemã. Assim nossa sociedade deve sempre dar continuidade ao caráter alemão como algo sagrado. (Revista Sport Club Germania, 1929, p.51)

"A força da juventude garante o futuro de um povo" era a máxima sobre a qual se baseava o trabalho do Germania, e que frequentemente aparecia nas publicações do Clube escritas por seus dirigentes. O discurso trazido por Engelhardt, bem como por outros presidentes era carregado de patriotismo, um discurso que pode ser encontrado nas exortações feitas por Jahn, na Alemanha do século XIX. Pelas fontes consultadas e aqui trabalhadas, parece-nos que 
os dirigentes do Clube buscavam um discurso que pudesse dirigir a atenção dos leitores para a importância da prática de exercícios físicos como meio de formação da colônia alemã e, particularmente, da formação dos jovens da "nova pátria". Para Engelhardt, por exemplo, era obrigação do clube dedicar-se também à formação física dos jovens brasileiros, sendo um lar de mentalidade e espírito alemães, buscando contribuir ativamente para o desenvolvimento da colônia e da nova pátria. Como eles atingiriam esse objetivo? Através da ginástica e do esporte, entendidos pelo clube como atividades criadoras de corpos saudáveis que contribuiriam, também, para a consolidação de um bom caráter. Para o Germania, movimento significava vida, portanto, força física, vigor físico, nada mais eram do que expressões de saúde concentrada.

A força e o vigor físicos, entretanto, não bastavam para que um indivíduo fosse considerado completo: ele também deveria ser espiritualmente completo. Desse modo, seria possível inferir que aqui, o clube toma como referencia as ideias do pedagogo, Guts Muths, idealizador da ginástica na Alemanha ainda no final do século XVIII e autor do livro "Ginástica para a Juventude"14.

Guts Muths, sem dúvida, sintonizado com as ideias preconizadas por Rousseau ao fim do século XVIII, defendia os exercícios físicos como parte fundamental da educação da juventude. Para ele o homem era uma unidade física e espiritual e, portanto, sua formação deveria considerar amplamente, a busca pelo equilíbrio intelectual, moral e físico. Assim, a clássica leitura de que um corpo debilitado, um corpo fraco leva, sem duvida, à debilidade da alma, foi também realizada pelo Germania que via como sua função, prevenir e mesmo impedir a degeneração de seus membros. A partir dessa compreensão acerca dos modos de se educar um ser humano supostamente completo, o clube tinha como proposta fazer para o corpo o que a escola fazia para a mente. Essa busca levava o clube a abrir suas portas aos estudantes da colônia, promovendo eventos,

\footnotetext{
${ }^{14}$ Nesta obra, Guts Muths faz constantes referências à busca de um cidadão física e espiritualmente completo, que poderia ser formado a partir da ginástica.
} 
festas, torneios, entre outras atividades, tais como a Taça Friese ${ }^{15}$ e as Olimpíadas Juvenis ${ }^{16}$.

Outra preocupação de Engelhardt era a de fazer do clube um "lar" para a colônia alemã e sua direção assumia como de sua responsabilidade a obrigação de fazer do clube um lugar alegre, rodeado da mais bela natureza e, ao mesmo tempo, um lar no qual os alemães da colônia poderiam praticar diferentes atividades, inclusive esportivas e gímnicas. O Clube deveria, também, para além de tudo isso, ser um "jardim", onde aqueles que não tivessem mais condições de se dedicar às práticas corporais pudessem passar o tempo com a comunidade, usufruindo dos benefícios que a natureza oferece. Somente conquistando essa característica de lar, o clube conseguiria alcançar seus objetivos mais caros e, aparentemente, Engelhardt foi bem-sucedido, pois, a Revista Educação Física de 1941, assim descreve o clube:

Numa área de cento e quarenta mil metros quadrados estão situadas presentemente as modernas instalações do clube que é motivo de justificado orgulho do esporte brasileiro - Sport Club Germania. Os que demandam o aristocrático bairro do Jardim Europa e que, pela primeira vez se integram na majestosa grandeza daquele clube, tem justa noção dos ilimitados horizontes do esporte quando praticado com o sentido racional e puro da cultura física. Tudo ali é grande e perfeito. Roseirais que se enfileiram a perder de vista; flores e arvores em perfeita harmonia de tons e formas, calor e sombra, refletindo, em conjunto, um bom gosto que se evidencia nos menores detalhes. É um hiato na metrópole. O lindo recanto do Jardim Europa, transformado pela vontade de sua gente, em uma pausa de recolhimento e suavidade, em que se casam a harmonia dos seus jardins bem plantados com o verde sugestivo da mata tropical, poderia ser

\footnotetext{
${ }^{15} \mathrm{~A}$ Taça Friese era uma competição de futebol entre os alunos das escolas alemãs de São Paulo. O nome é em homenagem a Hermann Friese, jogador do Germania na primeira década do século XX.

${ }^{16} \mathrm{~A} 1^{\text {a }}$ Olimpíada Juvenil do Germania foi realizada em 1932, contava com 613 participantes inscritos e tinha competições de atletismo, futebol, ginástica, natação e tênis. No total foram realizadas 10 edições das Olimpíadas Juvenis do Germania, sendo que a última aconteceu em 1941.
}

Movimento, Porto Alegre, v. 16, n. 03, p. 89-108, julho/setembro de 2010. 
egoisticamente, reservado ao devaneio e ao conforto dos seus associados. Não o é, entretanto. Em etapas sucessivas, cada qual mais notável, suas realizações assinalam o motivo fundamental de seus destinos - o de propugnar sem desfalecimentos para o progresso da educação física brasileira. (O que foi..., 1941)

Um espírito de camaradagem e a prática regular de atividades físicas eram, para o Germania, aspectos fundamentais para a formação de uma sociedade harmoniosa. Além de ser um ponto de encontro para os alemães da colônia de São Paulo, a direção do clube ainda via como sua função contribuir ativamente na formação de uma juventude forte e na propagação da prática de atividades corporais regulares que, para o clube, eram a base para a formação de um povo forte, tanto do ponto de vista físico, quanto moral e intelectual. Sendo um "lar" para a colônia alemã, também procurava atingir a juventude brasileira, buscando incorporar nesses jovens, os ideais e hábitos germânicos.

\section{Uma educação Corporal no Germania}

Os estatutos do Germania, desde seu início, apontavam para uma grande variedade de atividades a serem desenvolvidas dentro do clube em busca da promoção do esporte. Além da prática de diferentes atividades esportivas e gimnicas, eram comuns também as excursões para lugares próximos ao clube, assim como celebrações diversas nas quais se homenageava à terra natal, a fundação do clube, entre outras. Independente de qual fosse o motivo da celebração, o canto era uma atividade sempre presente e comum a todas elas. Nessas ocasiões, nos programas da festa, o clube trazia a "canção festiva", escrita por seus membros, cantada por todos e sempre fazendo referência à transformação do Brasil em nova pátria, assim como à camaradagem e fidelidade dos sócios para com o clube. Além do canto, as apresentações ginásticas também eram comuns nessas ocasiões.

Sendo o Germania um clube de origem alemã, supunha-se que

Wovimento, Porto Alegre, v. 16, n. 03, p. 89-108, julho/setembro de 2010. 
seriam encontradas inúmeras referências à prática da ginástica em seu interior, assim como em seus estatutos. Embora a ginástica tenha sido encontrada, não foi com o destaque que dela se esperava. Sabemos de sua presença no interior do clube pelos registros de apresentações em comemorações, de fotografias de aparelhos de ginástica no campo do clube entre as décadas de 1920 e 1930, além da existência de um "Departamento de Jogos e Ginástica para a Juventude". Não sabemos, entretanto, qual era a ação desse departamento, uma vez que não foram encontrados registros de suas atividades na documentação consultada.

Essa incerteza com relação à presença da ginástica no Germania levou-nos a questionar o porquê desta suposta secundarização em relação a uma atividade que era vista, na Alemanha do século XIX, como uma manifestação corporal genuinamente nacional. Uma resposta pode ser encontrada nas referências do próprio fundador, Hans Nobiling, quando da fundação do clube. O Germania, ao contrário dos outros clubes alemães existentes em São Paulo naquele mesmo período, fora fundado para a prática de uma atividade completamente diferente: o futebol. Nobiling, que chegou ao Brasil no final do século XIX, foi influenciado pelo florescimento do esporte na Alemanha ${ }^{17}$.

Aparentemente, a ginástica não possuía grande destaque entre as atividades do clube. Todavia, as apresentações gímnicas em suas festividades, bem como a presença de um Departamento de Jogos e Ginástica para a Juventude fazem-nos pensar que ela poderia, sim, ter algum papel em seu interior. Havia uma grande preocupação em estimular a prática de exercícios físicos regulares e introduzir as crianças nestas atividades, algo que poderia ser função da ginástica.

No ano de 1903, além do Departamento de Jogos e Ginástica para a Juventude, o clube também teve um departamento de Natação,

\footnotetext{
${ }^{17}$ Segundo Dixon (1981), o movimento esportivo floresce na Alemanha no final do século XIX espontaneamente em meio à população, sem apresentar um líder, ideais políticos ou qualquer filosofia explícita. $\mathrm{O}$ autor aponta que as práticas esportivas foram introduzidas pelos ingleses residentes no território alemão que levavam consigo a prática de seu esporte preferido e acabavam disseminando-o entre a população local.
} 
Futebol, Atletismo e Esgrima, além, é claro, dos departamentos de Remo e Tênis, criados quando de sua fundação em 1899.

A importância do futebol na constituição do Germania foi mesmo marcante. Logo em seu início, o clube já era membro da Liga Paulista de Foot-ball, sendo campeão dessa Liga nos anos de 1906 e 1915. Em seus estatutos encontramos algo bastante curioso acerca dessa "paixão" pelo futebol, uma vez que um dos cargos da diretoria do Germania era o de capitão do time, cujas responsabilidades eram de escalar o time, treiná-lo e representar o clube nas reuniões da Liga. Em dias de jogos, todos os membros presentes, fossem jogadores ou torcedores, respondiam ao capitão.

Outras práticas corporais importantes na constituição do clube são aquelas feitas na água. $\mathrm{O}$ remo e, especialmente, a natação tinham grande aceitação entre os membros do Germania. No ano de 1933, em comemoração à inauguração da piscina do clube, foram publicados em seus diversos veículos de divulgação, inúmeros artigos destacando a importância da natação. Outro aspecto que merece ser analisado é o fato de o Germania também lançar uma revista bilíngue, comemorativa da inauguração da piscina recémconstruída do clube, Zur Eröffnung des Schwimmbeckens (Comemoração da inauguração da piscina do S.C. Germania), periódico que se empenhava em informar sobre os benefícios da natação e, ainda, destacava a grande meta do clube, qual seja, a de educar o corpo e o espírito dos jovens da colônia em um local específico - a água - nos moldes alemães.

Ainda no final da década de 1930, o clube contrata o professor Erich Montag para ministrar aulas de natação para homens e mulheres de diversas idades, o que demonstra, também, que havia uma preocupação com a educação corporal de meninas e mulheres e que elas poderiam ser submetidas a práticas comuns. $\mathrm{O}$ remo também foi um esporte bastante enaltecido nas publicações do clube, sendo mesmo considerado como o verdadeiro "exercício ginástico", uma vez que mobiliza todas as partes do corpo ao mesmo tempo. Note-se aqui, uma inferência interessante acerca de uma compreensão da ginástica também como atividade de formação, como atividade de base. 


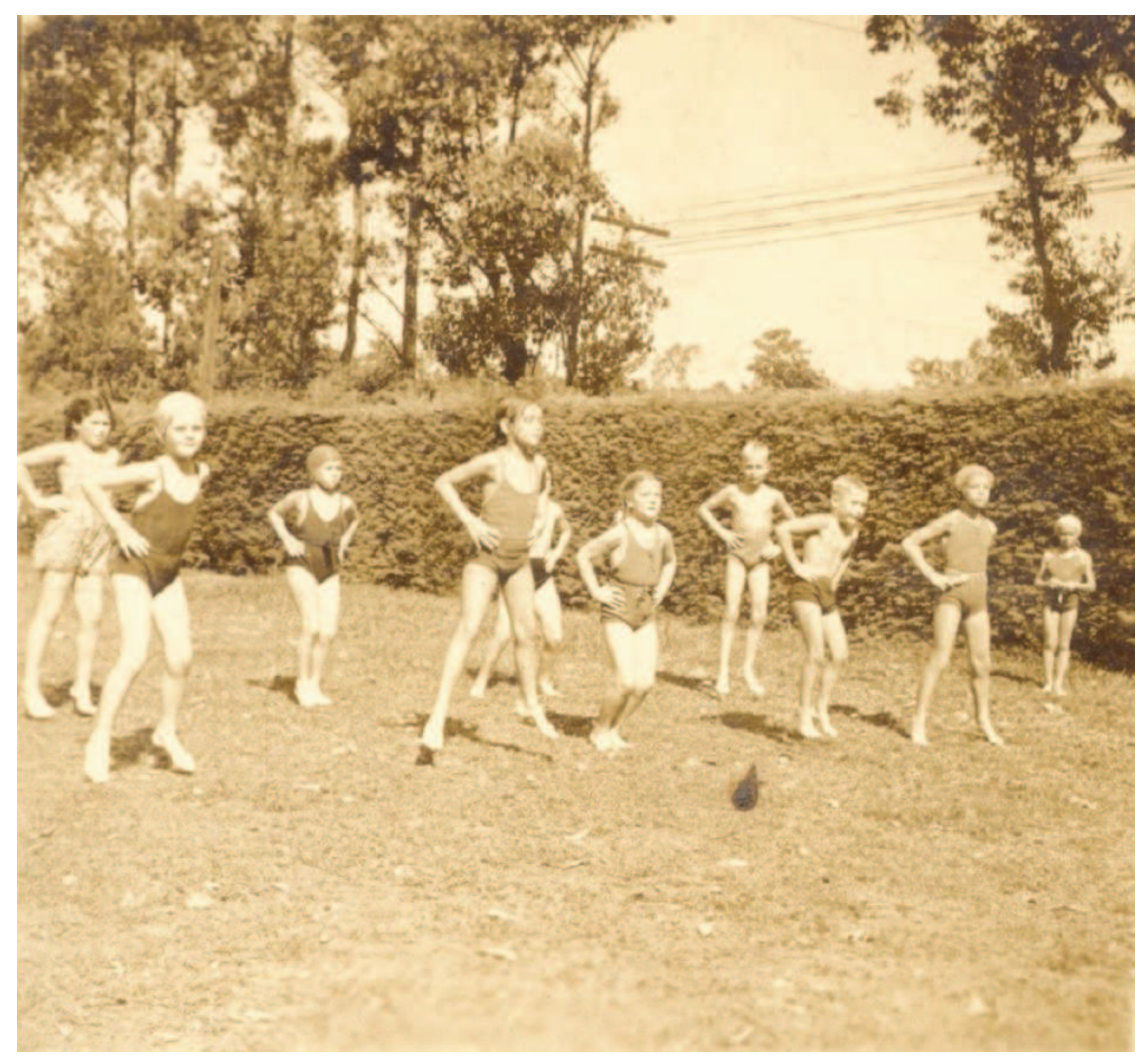

Figura 1: Ginástica preparatória para aulas de natação do senhor Erich Montag (1938). Centro Pró-Memória Hans Nobiling.

A diversidade de práticas corporais, esportivas ou não, encontrada nas fontes consultadas atesta também a prática do pentatlo, e que no Germania, consistia das provas de chute de bola de futebol, arremesso de rocha, corrida de 80 metros, salto em distância e arremesso de bola de críquete (programas esportivos do Sport Club Germania).

\section{ConSIDERAÇÕES FINAIS}

O Sport Club Germania constituiu-se, ao longo de sua existência, como importante ponto de reunião da colônia alemã de São Paulo. Em sua busca para tornar-se um "lar" com hábitos alemães, não só para os membros da colônia, mas também para os jovens da nova pátria, usava as publicações próprias e os jornais da colônia para 
difundir a importância da prática regular de exercícios físicos como forma de construir um ser humano completo, tanto física quanto moralmente.

Se os objetivos do clube eram os mesmos das outras associações alemãs recreativas do período, como o Turnverein e o Turnerschaft, o que o diferenciava estava já em suas origens, era a paixão que seu fundador nutria pelo futebol. Ao contrário dos outros clubes alemães do período, o Germania não tinha a ginástica como principal atividade, o que não significa dizer que esta prática fosse inexistente em seu interior e a presença de um departamento voltado para sua aplicação destinada aos jovens da colônia atesta, sem duvida, sua importância. Talvez para o Germania a ginástica não fosse uma atividade principal, mas, sim, uma base preparatória para a inserção de seus associados em outras manifestações esportivas, assim como forma de espetáculo, de exibição de performances corporais em eventos do clube. Por mais que Hans Nobiling buscasse, de certa forma, "fugir" da ginástica, a presença de pessoas ligadas a ela, como o próprio Max Engelhardt, e o intercâmbio com os clubes ginásticos alemães de São Paulo estimularam sua prática, ainda que pequena, no cotidiano do Germania.

As ideias de seus diretores apresentavam grande similaridade aos ideais defendidos por Guts Muths e Jahn no território alemão durante o século XIX. Assim, o clube seria um local de manutenção das tradições germânicas na nova pátria buscando, também pelas diversas práticas corporais ali desenvolvidas, propagar o modo de vida e o espírito, o caráter alemão, não apenas para sua juventude, mas também para a juventude da colônia. 
Arquivos e Fontes: Arquivo Público do Estado de São Paulo, Centro Pró-Memória Hans Nobiling, Instituto Martius-Staden.

\begin{tabular}{|c|c|}
\hline Documentos & Data \\
\hline - Relatório de Hans Nobiling sobre a origem do futebol em São Paulo & 08.1907 \\
\hline - Programa esportivo & 1901 \\
\hline - Canção festiva do Germania & 1902 \\
\hline - Estatutos do Sport Club Germania & 1904 \\
\hline - Programa de festa esportiva realizada no Parque Antártica & 1907 \\
\hline - 25 Jahre Sport Club Germania 1899-1924 & 1924 \\
\hline - Deutsche Zeitung & 08.09.1924 \\
\hline - Deutsche Zeitung & 18.01.1926 \\
\hline -Deutsche Zeitung & 1929 \\
\hline - Revista Sport Club Germania 1899-1929 & 1929 \\
\hline - Deutsche Zeitung & 16.03 .1929 \\
\hline - Sport Club Germania - Comemoração da inauguração da piscina do S.C.Germania & 1933 \\
\hline - Deutschen Tages & 03.04.1933 \\
\hline - Deutsche Zeitung & 09.10 .1933 \\
\hline - Deutsche Zeitung & 03.02 .1934 \\
\hline - Deutsche Zeitung & 26.12.1934 \\
\hline - Deutsche Zeitung & 03.09.1934 \\
\hline \multicolumn{2}{|l|}{ - Bestimmungen für die Auftragung des Germania Wander-Pries auf der Sport-Club } \\
\hline Germania veranstalteten Jugend-Olympiade & 04.1937 \\
\hline - OEstado de S.Paulo & 13.04.1937 \\
\hline - Documento da assembleia sobre a nacionalização do clube & 09.1938 \\
\hline - Resolvida a nacionalização do Germania & 22.09 .1938 \\
\hline - Parecer sobre a nacionalização do Germania & 23.09 .1938 \\
\hline -Estatutos da Sociedade Germania & 1939 \\
\hline - Documento da assembleia geral extraordinária & 1939 \\
\hline - Deustche Zeitung & 23.05 .1939 \\
\hline - Revista Sport Club Germania 1899-1940 & 1940 \\
\hline -Revista Sport Club Germania 1899-1940 & 1940 \\
\hline - Ata da assembleia de Fusão entre Sociedade Germania e Esporte Clube Pinheiros & 1942 \\
\hline - Deutsche Nachrichten & 1949 \\
\hline - Deutsche Nachrichten & 1954 \\
\hline - Deutsche Nachrichten & 1955 \\
\hline - Deutsche Nachrichten & 1959 \\
\hline
\end{tabular}


The Sport Club Germania and corporal education (1899-1938): traces of a club.

Abstract: This article aims to comprehend the physical practices developed at Sport Club Germania and analyze its possible relations to the gymnastics widely developed in Germany during the 19th century, a period of intense European immigration towards Brazil. Among these migratory waves, we can point out the German immigration which, although more intense towards the South region of the country, had also high influence in the development of São Paulo. Among the various institutions founded by these immigrants in the city of São Paulo, the clubs had high distinction as references not only to the practices of physical exercises but also to the preservation of the German traditions.

Keywords: Corporal Practices. German Immigration. Sport.

El Sport Club Germania y la educación del cuerpo
(1899-1938): Vestigios de un Club.
Resumen: este articulo tiene como objetivo
comprender las practicas corporales utilizadas en el
Sport Club Germania, y observar sus posibles relaci-
ones con la gimnasia desarrolladas en Alemania a lo
largo del siglo XIX (siglo este que marca un periodo de
intensa inmigración europea en dirección al Brasil).
Entre las corrientes inmigratorias que llegaron al país
podemos destacar la alemana, que a pesar de haber
sido más intensa en la región sur, también tuvieron
gran importancia en el estado de San Pablo. Entre las
diferentes instituciones fundadas por estos inmigrantes
en la capital paulista, los clubes tuvieron destaque
como referencias tanto para la practica de ejercicios
físicos como para la manutención de tradiciones
germánicas.
Palabras clave: Practicas corporales. Inmigración
alemana. Deporte

\section{REFERÊNCIAS}

DIXON, JG. Prussia, Politics and Physical Education. In: MCINTOSH, P. C. et al. Landmarks in the History of Physical Education. London: Routledge e Kegan Paul, 1981. p. 112-155.

ELIAS, Norbert. Os alemães: a luta pelo poder e a evolução do habitus nos séculos XIX e XX. Rio de Janeiro: Jorge Zahar, 1997. 
GUTS MUTHS, Johann Friedrich Christoph. (1793) Gymnastics for Youth. London: Stanley Paul , 1800.

JAHN, Friedrich Ludwig. (1816) Die deutsche Turnkunst. [s.I.] Sportverlag, 1960

LEONARD, Fred Eugene. A guide to the History of Physical Education. Philadelphia: Lea and Fabiger, 1927.

NICOLINI, Henrique: Tietê: o rio do esporte. São Paulo: Phorte, 2001.

PFISTER, Gertrud. German Turnen and Swedisch Gymnastics Concept, Development and Struggles in Europe. In: CONGRESSO BRASILEIRO DE HISTÓRIA DA EDUCAÇÃO FÍSICA, ESPORTE, LAZER E DANÇA, 7., 2000, Gramado/RS. Anais... . Porto Alegre: Universidade Federal do Rio Grande do Sul, 2000, p. 62-74.

O QUE foi o Pentatlo Atlético organizado em S. Paulo pelo S.C. Germania. Revista Educação Física, São Paulo, n. 59, p.40-41, 1941.

QUITZAU, Evelise Amgarten. As práticas corporais no Sport Club Germania (1900-1943). (Monografia) Campinas, Faculdade de Educação Física/Unicamp, 2008, 45p.

SEYFERTH, Giralda: Identidade étnica, assimilação e cidadania: a imigração alemã e o Estado brasileiro. (1993). Disponível em: <http://www.anpocs.org.br/ portal/publicacoes/rbcs_00_26/rbcs26_08.htm>. Acesso em: 19 ago. 2008.

Identidade étnica, assimilação e cidadania: a imigração alemã e o Estado brasileiro. Revista Brasileira de Ciências Sociais, São Paulo, v. 9, n. 26, p. 103122, 1994. Disponível em: http://www.anpocs.org.br/portal/publicacoes/ rbcs_00_26/rbcs26_08.htm. Acesso em: 19 ago. 2008

SIRIANI, Silvia Cristina Lambert: Uma São Paulo alemã: vida quotidiana dos imigrantes germânicos na região da capital (1827-1889). São Paulo: Arquivo do Estado, Imprensa Oficial do Estado, 2003.

SOARES, Carmen Lúcia. Imagens da educação no corpo. Campinas: Autores Associados, 2004

- Las corrientes gimnasticas europeas y su contenido: una historia de rupturas y permanencias. In: ROZENGARD, Rodolfo (Coord.). Apuntes de Historia para profesores de Educación Física. Buenos Aires: Miño y Dávila, 2006.

TESCHE, Leomar. O Turnen, a Educação e a Educação Física nas Escolas Teuto-Brasileiras no Rio Grande do Sul: 1852-1940. Ijuí: Unijuí, 2002.

Recebido em: 06.10.2009

Aprovado em: 27.03.2010

ovimento, Porto Alegre, v. 16, n. 03, p. 89-108, julho/setembro de 2010. 